\title{
Association between elevated serum alanine aminotransferase and cardiometabolic risk factors in rural Chinese population: a cross-sectional study
}

Shuang Chen, Xiaofan Guo, Xingang Zhang, Shasha Yu, Hongmei Yang, Mohan Jiang, Guozhe Sun and Yingxian Sun $^{*}$

\begin{abstract}
Background: Elevated alanine aminotransferase (ALT) levels may be associated with metabolic syndrome and cardiovascular diseases. This study aimed to investigate the association between elevated ALT levels and cardiometabolic risk factors in a rural Chinese population.
\end{abstract}

Methods: This was a cross-sectional study conducted from July 2012 to August 2013, including 11,573 subjects (5,357 men and 6,216 women) aged $\geq 35$ years in rural areas of Liaoning Province. A physical examination was performed and metabolic indicators were examined under standard protocols. Subjects were divided into those with elevated ALT levels (>40U/L) and those with normal ALT levels ( $\leq 40 \mathrm{U} / \mathrm{L})$.

Results: Participants with elevated ALT levels had higher levels of almost all cardiometabolic risk factors than those with normal ALT levels. In individuals with elevated ALT levels, weight, height, waist circumference, and body mass index (BMI), which are indicators for general and abdominal obesity, were significantly higher $(p<0.001)$ than those in individuals with normal ALT levels. There was no significant difference in race, current smoking, or physical activity between the two groups. Other cardiometabolic risk factors, such as systolic blood pressure, diastolic blood pressure, and fasting plasma glucose, TC, TG, low-density lipoprotein cholesterol, and serum uric acid levels, were higher in participants with elevated ALT levels than in those with normal ALT levels. Logistic regression analysis showed that male sex, younger age, and the presence of high TC, high TG, and low high-density lipoprotein cholesterol levels, current smoking status, BMI $\geq 25 \mathrm{~kg} / \mathrm{m}^{2}$, abdominal obesity, hyperuricemia, and $\mathrm{HtgW}$ phenotype were significantly $(p<0.05)$ associated with elevated ALT levels. Sex-related differences were also investigated. For men, hypertension (OR 1.33, $95 \% \mathrm{Cl} 1.08-1.62$ ), high TC levels (OR 1.63, $95 \% \mathrm{Cl}$ 1.23-2.17), high TG levels (OR 1.62, $95 \% \mathrm{Cl} 1.25-2.09$ ), $\mathrm{BMI} \geq 25 \mathrm{~kg} / \mathrm{m}^{2}$ (OR 1.52, $\left.95 \% \mathrm{Cl} 1.07-2.18\right)$, and hyperuricemia (OR 1.92, $\left.95 \% \mathrm{Cl} 1.52-2.40\right)$ were significantly $(p<0.05)$ related to elevated serum ALT levels, but this was not observed in women.

Conclusions: There are significant relationships of elevated ALT levels with cardiometabolic risk factors and several sex-related differences in rural Chinese. Elevated serum ALT levels are associated with a worse cardiac risk profile.

Keywords: Alanine aminotransferase, Cardiometabolic risk factors, Rural Chinese Population, Sex-related differences

\footnotetext{
* Correspondence: yxsun@mail.cmu.edu.cn

Department of Cardiology, The First Affiliated Hospital of China Medical University, 155 Nanjing North Street, Heping District, 110001 Shenyang, People's Republic of China
} 


\section{Background}

Alanine aminotransferase (ALT) is considered as a sensitive indicator of liver cell injury [1,2]. Because ALT is closely related to fat accumulation in the liver [3], it is also commonly considered as a surrogate marker for nonalcoholic fatty liver disease (NAFLD) in some epidemiological studies $[4,5]$. Recent findings have shown that nonalcoholic fatty liver disease is strongly associated with obesity, metabolic syndrome, and diabetes mellitus, as well as cardiovascular events [6-9]. Several studies have indicated that elevated serum ALT levels are associated with age, sex, obesity, waist circumference, fasting blood glucose levels, and serum triglyceride levels [10, 11]. Therefore, patients with cardiometabolic risk factors usually have elevated serum ALT activity, and serum ALT levels are commonly used to monitor liver function in people with metabolic disorders. However, there are limited data linking elevated serum ALT levels and physical activity [12]. The HtgW phenotype is represented by the simultaneous presence of elevated serum triglyceride levels and an increased waist circumference [13], and this phenotyope is a major determinant of cardiometabolic risk among Turks [14].

Several large-scale, population-based surveys have evaluated serum ALT levels in developed countries, but there are limited data from developing countries. In China, previous studies on ALT and cardiometabolic risk factors had limitations in the study design and a small sample size. Large-scale, population-based, cross-sectional surveys addressing the associations between elevated serum alanine aminotransferase levels and cardiometabolic risk factors in a rural Chinese population have not been performed. Therefore, we conducted this study to investigate 1) the association between elevated ALT levels and cardiometabolic risk factors in a rural Chinese population and 2) differences in cardiometabolic characteristics associated with elevated ALT levels in both sexes.

\section{Methods}

\section{Study population}

Liaoning Province is located in Northeast China. From July 2012 to August 2013, a representative sample aged $\geq 35$ years was selected to describe the prevalence, incidence and natural history of cardiovascular risk factors in rural areas of Liaoning Province, which is called Northeast China Rural Cardiovascular Health Study (NCRCHS). The study adopted a multi-stage, stratified randomly cluster-sampling scheme. In the first stage, 3 counties (Dawa, Zhangwu, and Liaoyang County) were selected from the eastern, southern, and northern region of Liaoning province. In the second stage, one town was randomly selected from each county (a total of 3 towns). In the third stage, 8-10 rural villages from each town were randomly selected (a total of 26 rural villages). All the eligible permanent residents aged $\geq 35$ years from each village were invited to attend the study (a total of 14,016 participants). Of those, 11,956 participants agreed and completed the present study and the response rate was $85.3 \%$. The study was approved by the Ethics Committee of China Medical University (Shenyang, China). All procedures were performed in accordance with the ethical standards. Written consent was obtained in all participants after they had been informed of the objectives, benefits, medical items and confidentiality agreement of personal information. If the participants were illiterate, we obtained the written informed consents from their proxies. In this report, we used data of baseline and only participants with a complete set of data regarding the variables analyzed in the study were included, making a final sample size of 11,573 (5,357 men and 6,216 women).

\section{Data collection and measurements}

Data was collected during a single clinic visit by cardiologists and trained nurses using a standard questionnaire by face-to-face interview. Before the survey was performed, we invited all eligible investigators to attend the organized training. The training contents included the purpose of this study, how to administer the questionnaire, the standard method of measurement, the importance of standardization, and the study procedures. A strict test was evaluated after this training, only those who scored perfectly on the test could become investigators. During data collection, our inspectors had further instructions and support.

Data on demographic characteristics, lifestyle risk factors, family income, medical history, were obtained by interview with a standardized questionnaire. There was a central steering committee with a subcommittee for quality control. Educational level was divided into primary school or below, middle school and high school or above. Family income was classified as $\leq 5000,5000-$ 20000 and $>20000 \mathrm{CNY} /$ year.

According to American Heart Association protocol, blood pressure was measured three times at 2-min intervals after at least $5 \mathrm{~min}$ of rest using a standardized automatic electronic sphygmomanometer (HEM-741C; Omron, Tokyo, Japan). The calibration of the Omron device was checked using a standard mercury sphygmomanometer every month by two doctors according to the British Hypertension Society protocol [15]. The participants were advised to avoid caffeinated beverages and exercise for at least 30 min before the measurement. During the measurement, the participants were seated with the arm supported at the level of the heart. The mean of three BP measures was calculated and used in all analyses.

Weight and height were measured to the nearest $0.5 \mathrm{~kg}$ and $0.1 \mathrm{~cm}$ respectively with the participants in 
light weight clothing and without shoes. WC was measured at the midpoint between the lower rib and upper margin of the iliac crest using a non-elastic tape (to the nearest $0.1 \mathrm{~cm}$ ), with the participants standing at the end of normal expiration. The body mass index (BMI) was calculated as weight in kilograms divided by the square of the height in meters.

Fasting blood samples were collected in the morning after at least $12 \mathrm{~h}$ of fasting for all participants. Blood samples were obtained from an Antecubital vein into Vacutainer tubes containing EDTA. Serum was subsequently isolated from the whole blood, and all serum samples were frozen at $-20{ }^{\circ} \mathrm{C}$ for testing at a central, certified laboratory. Fasting plasma glucose (FPG), total cholesterol (TC), low-density lipoprotein cholesterol (LDL-C), high-density lipoprotein cholesterol (HDL-C), triglyceride (TG), Serum uric acid(SUA) and other routine blood biochemical indexes were analyzed enzymatically on an Olympus AU640 autoanalyzer (Olym-pus, Kobe, Japan). All laboratory equipment was calibrated and blinded duplicate samples were used.

\section{Definitions}

According to JNC-7 report [16], hypertension was defined as SBP $\geq 140 \mathrm{~mm} \mathrm{Hg}$ and/or DBP $\geq 90 \mathrm{~mm} \mathrm{Hg}$ and/or use of antihypertensive medications. Diabetes mellitus was diagnosed according to the WHO criteria [17]: $\mathrm{FPG} \geq 7 \mathrm{mmol} / \mathrm{L}(126 \mathrm{mg} / \mathrm{dL})$ and/or being on treatment for diabetes. High TC was defined as TC $\geq 6.21 \mathrm{mmol} / \mathrm{L}(240 \mathrm{mg} / \mathrm{dL})$. High TG was defined as TG $\geq 2.26 \mathrm{mmol} / \mathrm{L}(200 \mathrm{mg} / \mathrm{dL})$. High LDL-C was de fined as LDL-C $\geq 4.16 \mathrm{mmol} / \mathrm{L}(160 \mathrm{mg} / \mathrm{dL})$. Low HDL-C was defined as HDL-C $<1.03 \mathrm{mmol} / \mathrm{L}(40 \mathrm{mg} / \mathrm{dL})$ [18]. Hyperuricemia was defined as serum uric acid $\geq 416 \mu \mathrm{mol} / \mathrm{l}$ in men and $\geq 357 \mu \mathrm{mol} / \mathrm{l}$ in women according to guidelines [19]. BMI was categorized into 3 groups as normal $\left(\mathrm{BMI}<25 \mathrm{~kg} / \mathrm{m}^{2}\right)$, overweight $\left(25 \leq \mathrm{BMI}<30 \mathrm{~kg} / \mathrm{m}^{2}\right)$ and obesity (BMI $\geq 30 \mathrm{~kg} / \mathrm{m}^{2}$ ), according to the World Health Organization (WHO) criteria [20]. Abdominal obesity was defined as WC $\geq 88 \mathrm{~cm}$ for females and WC $\geq 102 \mathrm{~cm}$ for males [21]. HtgW phenotype was defined as fasting triglycerides $\geq 1.7 \mathrm{mM}$ combined with abdominal obesity. Elevated serum ALT level was defined as ALT $>40$ U/L [22].

The smoking and alcohol consumption status were also surveyed. Self-reported smoking and drinking were obtained from the questionnaire. Current smokers or drinkers were defined as people who were currently smoking or drinking. Former and never smokers or drinkers were treated as the other category.

Physical activity included occupational and leisuretime physical activity. A detailed description of the methods for assessing physical activity has been presented elsewhere. Occupational and leisure-time physical activity were merged and regrouped into the following three categories: 1) low-subjects who reported light levels of both occupational and leisure-time physical activity, 2) moderate-subjects who reported moderate or high levels of either occupational or leisure-time physical activity and 3) high-subjects who reported a moderate or high level of both occupational and leisure-time physical activity [23].

\section{Statistical analysis}

Descriptive statistics were calculated for all the variables, including continuous variables which were normally distributed (reported as mean values and standard deviations) and categorical variables (reported as numbers and percentages). Differences among ALT and sex categories were evaluated using Student's $t$-test, or the $x^{2}$ test as appropriate. Multivariate logistic regression analyses were used to identify the association between elevated ALT and caridometabolic risk factors with odds ratios (ORs) and corresponding $95 \%$ confidence intervals (CIs) calculated. All the statistical analyses were performed using SPSS version 17.0 software (SPSS Inc, Chicago, Illinois, USA), and $P$ values less than 0.05 were considered to be statistically significant.

\section{Results}

\section{Baseline characteristics of the study population}

Table 1 shows baseline data according to serum ALT levels and sex. A total of 11,573 subjects (5,357 men and 6,216 women) participated in the study. The general characteristics of the study population with and without elevated serum ALT levels are shown in Table 1. The overall prevalence of elevated ALT levels $(\geq 40 \mathrm{U} / \mathrm{L})$ was $7.4 \%(n=860)$. Subjects with elevated serum ALT levels were more likely to be men (men, $10.5 \%$ vs women, $4.8 \%, \mathrm{p}<0.001$ ), and had a higher percentage of current drinking compared with those with normal serum ALT levels. Additionally, subjects with elevated ALT levels had higher levels of SBP, DBP, and FPG, TC, TG, LDL-C, and serum uric acid levels, but lower HDL-C levels than those with normal ALT levels. Furthermore, subjects with elevated ALT levels had a heavier weight, taller height, greater waist circumference, and higher BMI compared with those with normal serum ALT levels.

\section{Adjusted Odd ratios of associated cardiometabolic risk factors for elevated serum ALT levels}

Table 2 shows the adjusted ORs for the associations between elevated serum ALT levels and certain cardiometabolic risk factors. Subjects with elevated serum ALT levels had higher levels of almost all cardiometabolic risk factors than those with normal serum ALT levels. Participants who had elevated serum ALT levels showed a more pronounced prevalence of hypertension 
Table 1 Characteristics of participants according to the serum levels of ALT

\begin{tabular}{|c|c|c|c|c|c|c|c|}
\hline Variables & $\begin{array}{l}\text { Total } \\
(n=11573)\end{array}$ & $\begin{array}{l}\mathrm{ALT} \leq 40 \\
(n=10713)\end{array}$ & $\begin{array}{l}\mathrm{ALT}>40 \\
(n=860)\end{array}$ & $P$ value & $\begin{array}{l}\text { Male } \\
(n=5357)\end{array}$ & $\begin{array}{l}\text { Female } \\
(n=6216)\end{array}$ & $P$ value \\
\hline Age (year) & & & & $<0.001$ & & & $<0.001$ \\
\hline $35-44(\%)$ & $2751(23.8)$ & $2487(23.2)$ & 264(30.7) & & $1218(22.7)$ & 1533(24.7) & \\
\hline $45-54(\%)$ & $3598(31.1)$ & $3292(30.7)$ & $306(35.6)$ & & $1621(30.3)$ & 1977(31.8) & \\
\hline $55-64(\%)$ & $3481(30.0)$ & $3257(30.4)$ & $224(26.0)$ & & 1634(30.5) & $1847(29.7)$ & \\
\hline$\geq 65(\%)$ & 1743(15.1) & $1677(15.7)$ & $66(7.7)$ & & $884(16.5)$ & $859(13.8)$ & \\
\hline Sex & & & & $<0.001$ & & & \\
\hline male(\%) & $5357(46.3)$ & $4794(44.7)$ & $563(65.5)$ & & & & \\
\hline female(\%) & $6216(53.7)$ & $5919(55.3)$ & $297(34.5)$ & & & & \\
\hline Race & & & & 0.431 & & & 0.645 \\
\hline $\operatorname{Han}(\%)$ & 10968(94.8) & 10148(94.7) & $820(95.3)$ & & $5071(94.7)$ & 5897(94.9) & \\
\hline Others(\%) & $605(5.2)$ & $565(5.3)$ & $40(4.7)$ & & 286(5.3) & $319(5.1)$ & \\
\hline Current smoking status (\%) & 4086(35.3) & $3757(35.1)$ & $329(38.3)$ & 0.060 & $3056(57.0)$ & 1030(16.6) & $<0.001$ \\
\hline Current drinking status (\%) & $2617(22.6)$ & 2333(21.8) & 284(33.0) & $<0.001$ & 2434(45.4) & 183(2.9) & $<0.001$ \\
\hline Education (\%) & & & & $<0.001$ & & & $<0.001$ \\
\hline Primary school or below & $5763(49.8)$ & $5391(50.3)$ & $372(43.3)$ & & $2232(41.7)$ & $3531(56.8)$ & \\
\hline Middle school & $4717(40.8)$ & $4325(40.4)$ & 392(45.6) & & 2512(46.9) & 2205(35.5) & \\
\hline High school or above & 1093(9.4) & $997(9.3)$ & $96(11.2)$ & & $613(11.4)$ & $480(7.7)$ & \\
\hline Physical activity (\%) & & & & 0.886 & & & $<0.001$ \\
\hline Low & $3441(29.7)$ & 3192(29.8) & 249(29.0) & & $1209(22.6)$ & $2232(35.9)$ & \\
\hline Moderate & $7479(64.6)$ & $6912(64.5)$ & $567(65.9)$ & & $3851(71.9)$ & $3628(58.4)$ & \\
\hline High & $653(5.7)$ & $609(5.7)$ & $44(5.1)$ & & 297(5.5) & $356(5.7)$ & \\
\hline Family income (CNY/year, \%) & & & & $<0.001$ & & & $<0.001$ \\
\hline$\leq 5000$ & $1441(12.5)$ & 1367(12.8) & $74(8.6)$ & & $720(13.4)$ & $721(11.6)$ & \\
\hline $5000-20000$ & $6306(54.5)$ & $5864(54.7)$ & $442(51.4)$ & & 2870(53.6) & $3436(55.3)$ & \\
\hline$>20000$ & $3826(33.0)$ & $3482(32.5)$ & $344(40.0)$ & & 1767(33.0) & 2059(33.1) & \\
\hline Diabetes & 1199(10.4) & 1074(10.0) & $125(14.5)$ & $<0.001$ & $529(9.9)$ & $670(10.8)$ & 0.119 \\
\hline Hypertension & $5914(51.1)$ & $5409(50.5)$ & $505(58.7)$ & $<0.001$ & 2889(53.9) & $3025(48.7)$ & $<0.001$ \\
\hline Weight(kg) & $64.1 \pm 11.4$ & $63.5 \pm 11.0$ & $71.5 \pm 13.3$ & $<0.001$ & $68.6 \pm 11.1$ & $60.3 \pm 10.1$ & $<0.001$ \\
\hline Height(cm) & $160.6 \pm 8.2$ & $160.4 \pm 8.2$ & $163.5 \pm 8.3$ & $<0.001$ & $166.4 \pm 6.3$ & $155.6 \pm 6.1$ & $<0.001$ \\
\hline $\mathrm{BMI}(\mathrm{Kg} / \mathrm{m} 2)$ & $24.8 \pm 3.7$ & $24.7 \pm 3.6$ & $26.7 \pm 4.2$ & $<0.001$ & $24.7 \pm 3.5$ & $24.9 \pm 3.8$ & $<0.001$ \\
\hline WC(cm) & $82.4 \pm 9.8$ & $82.0 \pm 9.7$ & $88.0 \pm 10.1$ & $<0.001$ & $83.8 \pm 9.8$ & $81.3 \pm 9.7$ & $<0.001$ \\
\hline $\mathrm{SBP}(\mathrm{mmHg})$ & $141.8 \pm 23.5$ & $141.5 \pm 23.5$ & $144.8 \pm 22.1$ & $<0.001$ & $143.7 \pm 22.6$ & $140.1 \pm 24.0$ & $<0.001$ \\
\hline $\mathrm{DBP}(\mathrm{mmHg})$ & $82.1 \pm 11.8$ & $81.7 \pm 11.7$ & $85.9 \pm 12.0$ & $<0.001$ & $83.8 \pm 11.8$ & $80.6 \pm 11.5$ & $<0.001$ \\
\hline FPG (mmol/L) & $5.9 \pm 1.6$ & $5.9 \pm 1.6$ & $6.1 \pm 1.6$ & $<0.001$ & $6.0 \pm 1.7$ & $5.9 \pm 1.6$ & 0.004 \\
\hline $\mathrm{TC}(\mathrm{mmol} / \mathrm{L})$ & $5.2 \pm 1.1$ & $5.2 \pm 1.1$ & $5.5 \pm 1.3$ & $<0.001$ & $5.2 \pm 1.0$ & $5.3 \pm 1.1$ & $<0.001$ \\
\hline TG $(\mathrm{mmol} / \mathrm{L})$ & $1.6 \pm 1.5$ & $1.6 \pm 1.4$ & $2.3 \pm 2.1$ & $<0.001$ & $1.7 \pm 1.6$ & $1.6 \pm 1.3$ & 0.145 \\
\hline LDL-C (mmol/L) & $2.9 \pm 0.8$ & $2.9 \pm 0.8$ & $3.1 \pm 0.9$ & $<0.001$ & $2.9 \pm 0.8$ & $3.0 \pm 0.8$ & $<0.001$ \\
\hline $\mathrm{HDL}-\mathrm{C}(\mathrm{mmol} / \mathrm{L})$ & $1.4 \pm 0.4$ & $1.4 \pm 0.4$ & $1.3 \pm 0.4$ & $<0.001$ & $1.4 \pm 0.4$ & $1.4 \pm 0.3$ & 0.645 \\
\hline Serum uric acid (mg/dL) & $291.9 \pm 84.9$ & $288.1 \pm 82.6$ & $338.9 \pm 97.8$ & $<0.001$ & $333.7 \pm 83.5$ & $255.8 \pm 67.8$ & $<0.001$ \\
\hline
\end{tabular}

Data are expressed as the mean \pm SD or as $n(\%)$

Abbreviations: $C N Y$ China Yuan (1CNY = 0.161 USD); SBP systolic blood pressure; DBP diastolic blood pressure; BMI body mass index; WC waist circumference; $T C$ total cholesterol; TG triglyceride; $L D L-C$ low-density lipoprotein cholesterol; HDL-C high-density lipoprotein cholesterol; FPG fasting plasma glucose 
Table 2 Adjusted ORs of Associated cardiometabolic risk Factors for Elevated Serum ALT Level (Q40 U/L)

\begin{tabular}{llll}
\hline Variables & OR & $95 \% \mathrm{Cl}$ & $\mathrm{P}$ \\
\hline Age, yrs & 0.96 & $0.95-0.97$ & $<0.001$ \\
Sex & & & \\
female & 1 (referent) & - & - \\
male & 2.98 & $2.44-3.64$ & $<0.001$ \\
Race & & & \\
Han & 1 (referent) & - & - \\
Others & 0.78 & $0.55-1.10$ & 0.158 \\
Current smoking status & 0.73 & $0.62-0.86$ & $<0.001$ \\
Current drinking status & 1.12 & $0.93-1.35$ & 0.233 \\
Hypertension & 1.30 & $1.11-1.53$ & 0.001 \\
diabetes & 1.22 & $0.98-1.52$ & 0.073 \\
High TC & 1.57 & $1.26-1.96$ & $<0.001$ \\
High TG & 1.59 & $1.28-1.96$ & $<0.001$ \\
Low HDL & 1.27 & $1.03-1.55$ & 0.022 \\
High LDL & 0.89 & $0.60-1.34$ & 0.592 \\
BMI $\geq 25$ kg/m2 & 1.51 & $1.18-1.94$ & 0.001 \\
Abdominal obesity & 1.53 & $1.19-1.96$ & 0.001 \\
Hyperuricemia & 1.78 & $1.47-2.16$ & $<0.001$ \\
HtgW phenotype & 1.37 & $1.07-1.76$ & 0.012 \\
\hline Adjusted for age, sex, race, BMl & $C u r$ smokng stas, Curent dinkng &
\end{tabular}

Adjusted for age, sex, race, BMI, Current smoking status, Current drinking status, Education, Physical activity, Family income, Hypertension, diabetes, high TC, high TG, low HDL, high $\mathrm{LDL}, \mathrm{BMI} \geq 25 \mathrm{~kg} / \mathrm{m}^{2}$, abdominal obesity, Hyperuricemia and $\mathrm{HtgW}$ phenotype

(adjusted OR, 1.30; 95 \% CI, 1.11-1.53), hypercholesterolemia (adjusted OR, 1.57; $95 \%$ CI, 1.26-1.96), hypertriglyceridemia (adjusted OR, 1.59; 95 \% CI, 1.281.96), low HDL-C levels (adjusted OR, 1.27; 95 \% CI, 1.03-1.55), BMI $\geq 25 \mathrm{~kg} / \mathrm{m}^{2}$ (adjusted OR, 1.51; $95 \%$ CI, 1.18-1.94), abdominal obesity (adjusted OR, 1.53; 95 \% CI, 1.19-1.96), hyperuricemia (adjusted OR, 1.78; $95 \%$ CI, 1.47-2.16), and HtgW phenotype (adjusted OR, 1.37; $95 \%$ CI, 1.07-1.76) compared with those with normal serum ALT levels, after adjusting for sex, age, race, BMI, current smoking status, current drinking status, hypertension, diabetes, education, physical activity, and income.

\section{Association between elevated ALT levels and cardiometabolic risk factors according to sex}

Subsequent to adjustment for confounding factors, the data showed dramatically different results in multiple logistic regression according to sex (Table 3). For men, cardiometabolic risk factors that were associated with elevated ALT levels included age (OR,0.95; $95 \%$ CI, 0.94-0.96), current smoking status (OR,0.62; $95 \% \mathrm{CI}, 0.52-0.75)$, hypertension (adjusted OR, 1.33; $95 \%$ CI, 1.08-1.62), hypercholesterolemia (adjusted OR, 1.63; 95 \% CI, 1.23-
2.17), hypertriglyceridemia (adjusted OR, 1.62; $95 \% \mathrm{CI}$, $1.25-2.09$ ), BMI $\geq 25 \mathrm{~kg} / \mathrm{m}^{2}$ (adjusted OR, 1.52; $95 \% \mathrm{CI}$, 1.07-2.18), and hyperuricemia (adjusted OR, 1.92; $95 \%$ CI, 1.54-2.40). However, for women, cardiometabolic risk factors that were significantly related to elevated ALT levels included age (OR, 0.98; 95 \% CI, 0.97-0.99), hypertriglyceridemia (adjusted OR, 1.74; 95 \% CI, 1.302.33), BMI $\geq 25 \mathrm{~kg} / \mathrm{m}^{2}$ (adjusted OR, 1.81; $95 \% \mathrm{CI}$, 1.27-2.58), and abdominal obesity (adjusted OR, 1.75; $95 \%$ CI, 1.30-2.35).

\section{Discussion}

To the best of our knowledge, the present study is the first large-scale, population-based, cross-sectional survey to report the relationships between elevated serum ALT levels and cardiometabolic risk factors in a rural area of China.

Elevated serum ALT levels are most closely related to liver fat accumulation and are commonly used as a surrogate marker for nonalcoholic fatty liver disease in epidemiological studies [22, 24]. Our study examined significant associations of elevated serum ALT levels with cardiometabolic risk factors in a rural Chinese population. After adjustment for various confounders, most of these associations remained significant. Sex and age-adjusted current smoking were significantly related to a lower likelihood of elevated serum ALT levels. Although current smoking might constitute an important risk factor with regard to liver function abnormalities [25], this is not surprising because smoking lowers the risk of type- 2 diabetes, presumably by inhibiting autoimmune processes [26]. Previous studies have found that elevated ALT levels are associated with obesity and metabolic syndrome, including a study performed in the Japanese population [27] and a population-based crosssectional survey in Korean adolescents [28].

The central characteristics of metabolic syndrome are hypertension, hyperglycemia, dyslipidemia, and abdominal obesity. Consistent with the results of other epidemiological studies [27, 29], our study showed positive associations between elevated serum ALT levels and cardiometabolic risk factors, such as hypertension, hypercholesterolemia, hypertriglyceridemia, low HDL-C levels, and abdominal obesity. Diabetes is inversely predicted by lipoprotein(a) [30-32] and is strongly predicted by $\mathrm{HtgW}$, which is also inversely predicted by lipoprotein(a). ALT is assumed to be collinear with Lp(a) and thereby acts as a mediator for cardiovascular risk factors, including the HtgW phenotype. However, an association between elevated ALT levels and diabetes mellitus was not found in our study.

In addition, we investigated the effect of sex on the associations of elevated serum ALT levels with cardiometabolic risk factors in a rural Chinese population. The overall prevalence of elevated ALT levels in our study 
Table 3 Association between elevated ALT level and cardiometabolic risk factors according to the sex

\begin{tabular}{|c|c|c|c|c|c|c|}
\hline \multirow[t]{2}{*}{ Variables } & \multicolumn{3}{|l|}{ Male } & \multicolumn{3}{|l|}{ Female } \\
\hline & OR & $95 \% \mathrm{Cl}$ & $\mathrm{P}$ & OR & $95 \% \mathrm{Cl}$ & $\mathrm{P}$ \\
\hline Age, yrs & 0.95 & $0.94-0.96$ & $<0.001$ & 0.98 & $0.97-0.99$ & 0.009 \\
\hline \multicolumn{7}{|l|}{ Race } \\
\hline Han & 1 (referent) & & 0.321 & 1 (referent) & & 0.415 \\
\hline Others & 0.78 & $0.51-1.19$ & 0.274 & 0.73 & $0.40-1.33$ & 0.309 \\
\hline Current smoking status & 0.62 & $0.52-0.75$ & $<0.001$ & 1.06 & $0.76-1.48$ & 0.733 \\
\hline Current drinking status & 1.12 & $0.92-1.32$ & 0.267 & 1.07 & $0.53-2.18$ & 0.842 \\
\hline Hypertension & 1.33 & $1.08-1.62$ & 0.006 & 1.22 & $0.93-1.61$ & 0.148 \\
\hline diabetes & 1.21 & $0.91-1.61$ & 0.192 & 1.23 & 089-1.76 & 0.195 \\
\hline High TC & 1.63 & $1.23-2.17$ & 0.001 & 1.38 & $0.96-1.99$ & 0.084 \\
\hline High TG & 1.62 & $1.25-2.09$ & $<0.001$ & 1.74 & $1.30-2.33$ & $<0.001$ \\
\hline Low HDL & 1.23 & $0.96-1.58$ & 0.096 & 1.33 & $0.93-1.89$ & 0.116 \\
\hline High LDL & 0.91 & $0.61-1.36$ & 0.640 & 1.21 & $0.78-1.89$ & 0.393 \\
\hline $\mathrm{BMI} \geq 25 \mathrm{~kg} / \mathrm{m} 2$ & 1.52 & $1.07-2.18$ & 0.021 & 1.81 & $1.27-2.58$ & 0.001 \\
\hline Abdominal obesity & 1.22 & $0.78-1.90$ & 0.377 & 1.75 & $1.30-2.35$ & $<0.001$ \\
\hline Hyperuricemia & 1.92 & $1.54-2.40$ & $<0.001$ & 1.34 & $0.90-1.99$ & 0.145 \\
\hline HtgW phenotype & 1.32 & $0.97-1.79$ & 0.077 & 1.500 & $0.97-2.00$ & 0.067 \\
\hline
\end{tabular}

Adjusted for age, race, BMI, Current smoking status, Current drinking status,Education,Physical activity, Family income, Hypertension, diabetes, high TC, high TG, low $\mathrm{HDL}$, high $\mathrm{LDL}, \mathrm{BMI} \geq 25 \mathrm{~kg} / \mathrm{m}^{2}$, abdominal obesity, Hyperuricemia and HtgW phenotype

(7.4 \% for men and women; $10.5 \%$ and $4.8 \%$, respectively) is similar to a previous population-based study that was conducted in the general Chinese population [2], but is much lower than another related study in China [33]. Multiple logistic regression analysis indicated that male sex, a younger age, the presence of hypertension, hypercholesterolemia, hypertriglyceridemia, low HDL-C levels, BMI $\geq 25 \mathrm{~kg} / \mathrm{m}^{2}$, abdominal obesity, hyperuricemia, and the $\mathrm{HtgW}$ phenotype were independent predictors of an elevated ALT level. Unsurprisingly, male sex and a younger age represented significant risk factors that were related to the likelihood of an elevated serum ALT level. These results are consistent with the results of other studies [9, 34]. Elevated serum ALT levels among predominantly younger male adults remain unexplained and deserve further attention [9]. Although our results relating to the significant association between elevated serum ALT levels and hyperuricemia appear to be similar to those of previous studies, the extent of elevation seems to be dependent on the severity of the hepatic lesions [2, 35]. Based on the sex-related data, differences in both sexes were present in the relationships between elevated serum ALT levels and cardiometabolic risk factors. For men, we found that elevated ALT levels were closely associated with age, current smoking status, hypertension, hypercholesterolemia, hypertriglyceridemia, BMI $\geq 25 \mathrm{~kg} / \mathrm{m}^{2}$, and hyperuricemia. However, for women, elevated ALT levels were mainly associated with age, hypertriglyceridemia, BMI $\geq 25 \mathrm{~kg} / \mathrm{m}^{2}$, and abdominal obesity.

Although current drinking status might be an important risk factor with regard to abnormalities of liver function in other population-based studies [2, 34], we did not find any significance for this risk factor in our study. In this sample of the rural Chinese population, we did not observe an association between elevated serum ALT levels and physical activity, even after adjustment for age and sex. To the best of our knowledge, data on the association between physical activity and serum ALT levels are limited. An inverse association between physical activity and serum ALT levels among middle-aged British women [11] and obese children [36] has been reported.

Several limitations in this study need to be acknowledged. First, because of the cross-sectional design of our study, we were unable to determine whether there was a causal association between elevated ALT levels and cardiometabolic risk factors. Therefore, the obtained associations in this study should be considered with caution. Second, despite extensive adjustment in our study, unmeasured confounders may explain part of the association between elevated ALT levels and cardiometabolic risk factors. There are known causes of elevated ALT levels that were not tested in our study, such as alcohol abuse, chronic viral hepatitis, and other illnesses. However, the strengths of this study are its population-based design, large sample size, and extensive information on confounders. 


\section{Conclusions}

In conclusion, there is a significant association between elevated ALT levels and cardiometabolic risk factors in rural Northeast China in both sexes. Individuals with elevated ALT levels have a higher risk of cardiometabolic abnormalities than those with normal ALT levels. Therefore, elevated serum ALT levels are associated with a worse cardiac risk profile. Further prospective studies are required to verify these findings.

\section{Competing interests}

The authors declare that they have no competing interests.

\section{Authors' contributions}

Shuang Chen analyzed data and drafted the manuscript. Xiaofan Guo and Xingang Zhang gave guidance on writing this paper. Shasha Yu, Hongmei Yang, Mohan Jiang, and Guozhe Sun performed the research. Yingxian Sun designed the research. All authors have read and approved the final manuscript.

\section{Acknowledgements}

This study was supported by grants from the "Twelfth Five-Year" project funds (National Science and Technology Support Program of China, Grant \#2012BAJ18B02) that Pro Yingxian Sun responsible for enable the project completion.

Received: 20 October 2014 Accepted: 29 June 2015

Published online: 10 July 2015

\section{References}

1. Kaplan MM. Alanine aminotransferase levels: what's normal? Ann Intern Med. 2002;137(1):49-51.

2. Liu CM, Tung TH, Liu JH, Chen VT, Lin CH, Hsu CT, et al. A community-based epidemiological study of elevated serum alanine aminotransferase levels in Kinmen, Taiwan. World J Gastroenterol. 2005;11(11):1616-22.

3. Andre P, Balkau B, Born C, Royer B, Wilpart E, Charles MA, et al. Hepatic markers and development of type 2 diabetes in middle aged men and women: a three-year follow-up study. The D.E.S.I.R. Study (Data from an Epidemiological Study on the Insulin Resistance syndrome). Diabetes Metab. 2005;31(6):542-50.

4. Adams LA, Waters OR, Knuiman MW, Elliott RR, Olynyk JK. NAFLD as a risk factor for the development of diabetes and the metabolic syndrome: an eleven-year follow-up study. Am J Gastroenterol. 2009;104(4):861-7.

5. Jeong SK, Nam HS, Rhee JA, Shin JH, Kim JM, Cho KH. Metabolic syndrome and ALT: a community study in adult Koreans. J Int Assoc Study Obesity. 2004;28(8):1033-8

6. Marchesini G, Brizi M, Bianchi G, Tomassetti S, Bugianesi E, Lenzi M, et al. Nonalcoholic fatty liver disease: a feature of the metabolic syndrome. Diabetes. 2001;50(8):1844-50.

7. Doi $Y$, Kubo M, Yonemoto K, Ninomiya T, Iwase M, Tanizaki $Y$, et al. Liver enzymes as a predictor for incident diabetes in a Japanese population: the Hisayama study. Obesity (Silver Spring, Md). 2007;15(7):1841-50.

8. Goessling W, Massaro JM, Vasan RS, D'Agostino Sr RB, Ellison RC, Fox CS. Aminotransferase levels and 20-year risk of metabolic syndrome, diabetes, and cardiovascular disease. Gastroenterology. 2008;135(6):1935-44. 1944.e1931.

9. Ruhl CE, Everhart JE. Determinants of the association of overweight with elevated serum alanine aminotransferase activity in the United States. Gastroenterology. 2003;124(1):71-9.

10. Church TS, Kuk JL, Ross R, Priest EL, Biltoft E, Blair SN. Association of cardiorespiratory fitness, body mass index, and waist circumference to nonalcoholic fatty liver disease. Gastroenterology. 2006;130(7):2023-30

11. Lawlor DA, Sattar N, Smith GD, Ebrahim S. The associations of physical activity and adiposity with alanine aminotransferase and gamma-glutamyltransferase. Am J Epidemiol. 2005;161(11):1081-8

12. Hong Z, Yanfang J, Shumei H, Jie S, Qing G, Xiangwei F, et al. Relationship between serum aminotransferase levels and metabolic disorders in northern China. J Turkish Society Gastroenterol. 2012;23(6):699-707.
13. Lemieux I, Pascot A, Couillard C, Lamarche B, Tchernof A, Almeras N, et al. Hypertriglyceridemic waist: $A$ marker of the atherogenic metabolic triad (hyperinsulinemia; hyperapolipoprotein B; small, dense LDL) in men? Circulation. 2000;102(2):179-84.

14. Onat A, Can G, Ornek E, Sansoy V, Aydin M, Yuksel H. Abdominal obesity with hypertriglyceridaemia, lipoprotein(a) and apolipoprotein A-I determine marked cardiometabolic risk. Eur J Clin Invest. 2013;43(11):1129-39.

15. O'Brien E, Petrie J, Littler W, de Swiet M, Padfield PL, Altman DG, et al. An outline of the revised British Hypertension Society protocol for the evaluation of blood pressure measuring devices. J Hypertens. 1993;11(6):677-9.

16. Chobanian AV, Bakris GL, Black HR, Cushman WC, Green LA, Izzo Jr JL, et al. Seventh report of the Joint National Committee on Prevention, Detection, Evaluation, and Treatment of High Blood Pressure. Hypertension. 2003;42(6):1206-52.

17. Alberti KG, Zimmet PZ. Definition, diagnosis and classification of diabetes mellitus and its complications. Part 1: diagnosis and classification of diabetes mellitus provisional report of a WHO consultation. J British Diabetic Assoc. 1998;15(7):539-53.

18. Executive Summary of The Third Report of The National Cholesterol Education Program (NCEP) Expert Panel on Detection, Evaluation, And Treatment of High Blood Cholesterol In Adults (Adult Treatment Panel III). JAMA 2001 285(19):2486-2497

19. Feig DI, Johnson RJ. Hyperuricemia in childhood primary hypertension. Hypertension. 2003;42(3):247-52.

20. Hypertension control. Report of a WHO Expert Committee. World Health Organ Tech Rep Ser. 1996;862:1-83.

21. Diet, nutrition and the prevention of chronic diseases. World Health Organization technical report series 2003 916:i-viii, 1-149, backcover

22. Chen ZW, Chen LY, Dai HL, Chen JH, Fang LZ. Relationship between alanine aminotransferase levels and metabolic syndrome in nonalcoholic fatty liver disease. J Zhejiang Univ Sci B. 2008;9(8):616-22.

23. Ainsworth BE, Haskell WL, Whitt MC, Irwin ML, Swartz AM, Strath SJ, et al. Compendium of physical activities: an update of activity codes and MET intensities. Med Sci Sports Exerc. 2000;32(9 Suppl):S498-504.

24. Fu CC, Chen MC, Li YM, Liu TT, Wang LY. The risk factors for ultrasounddiagnosed non-alcoholic fatty liver disease among adolescents. Ann Acad Med Singapore. 2009:38(1):15-7.

25. Ruhl CE, Everhart JE. Coffee and caffeine consumption reduce the risk of elevated serum alanine aminotransferase activity in the United States. Gastroenterology. 2005;128(1):24-32.

26. Onat A, Ozhan H, Esen AM, Albayrak S, Karabulut A, Can G, et al. Prospective epidemiologic evidence of a 'protective' effect of smoking on metabolic syndrome and diabetes among Turkish women-without associated overall health benefit. Atherosclerosis. 2007;193(2):380-8.

27. Saito T, Nishise $Y$, Makino N, Haga H, Ishii R, Okumoto K, et al. Impact of metabolic syndrome on elevated serum alanine aminotransferase levels in the Japanese population. Metabolism Clin Exp. 2009;58(8):1067-75.

28. Park HS, Han JH, Choi KM, Kim SM. Relation between elevated serum alanine aminotransferase and metabolic syndrome in Korean adolescents. Am J Clin Nutr. 2005;82(5):1046-51.

29. Liangpunsakul S, Chalasani N. Unexplained elevations in alanine aminotransferase in individuals with the metabolic syndrome: results from the third National Health and Nutrition Survey (NHANES III). Am J Med Sci. 2005:329(3):111-6.

30. Mora S, Kamstrup PR, Rifai N, Nordestgaard BG, Buring JE, Ridker PM. Lipoprotein(a) and risk of type 2 diabetes. Clin Chem. 2010;56(8):1252-60.

31. Onat A, Can G. Enhanced proinflammatory state and autoimmune activation: a breakthrough to understanding chronic diseases. Curr Pharm Des. 2014;20(4):575-84.

32. Onat A, Coban N, Can G, Yuksel M, Karagoz A, Yuksel H, et al. Low 'quotient' Lp(a) concentration mediates autoimmune activation and independently predicts cardiometabolic risk. Exp Clin Endocrinol Diabetes. 2015;123(1):11-8.

33. Chen YF, Hu YC, Shen HC, Chang HT, Tung TH. Clinical implications in the prevalence and associated cardiovascular factors of elevated serum alanine aminotransferase levels among elderly agricultural and fishing population in Taipei, Taiwan: experience at a teaching hospital. Am Federation Clin Res. 2014;62(1):88-96.

34. Zhang H, Ding Y, Li Q, Sun J, He S, Feng X, et al. Relationship between Serum Aminotransferase Levels and Metabolic Disorders in Northern China. Iranian J Public health. 2012;41(2):15-26. 
35. Bruckert E, Giral P, Ratziu V, Poynard T, Chapman MJ, Opolon P, et al. A constellation of cardiovascular risk factors is associated with hepatic enzyme elevation in hyperlipidemic patients. Metabolism Clin Exp. 2002;51(8):1071-6.

36. Lee YS, Kek BL, Poh LK, Saw SM, Loke KY. Association of raised liver transaminases with physical inactivity, increased waist-hip ratio, and other metabolic morbidities in severely obese children. J Pediatr Gastroenterol Nutr. 2008:47(2):172-8

Submit your next manuscript to BioMed Central and take full advantage of:

- Convenient online submission

- Thorough peer review

- No space constraints or color figure charges

- Immediate publication on acceptance

- Inclusion in PubMed, CAS, Scopus and Google Scholar

- Research which is freely available for redistribution 